\title{
Ultramicrosensors based on transition metal hexacyanoferrates for scanning electrochemical microscopy
}

\author{
Maria A. Komkova ${ }^{1}$, Angelika Holzinger², Andreas Hartmann², \\ Alexei R. Khokhlov ${ }^{3}$, Christine Kranz ${ }^{2}$, Arkady A. Karyakin ${ }^{1}$ \\ and Oleg G. Voronin ${ }^{*} 1, \S$
}

Open Access

\author{
Full Research Paper \\ Address: \\ ${ }^{1}$ Faculty of Chemistry, M.V. Lomonosov Moscow State University, \\ Moscow, Russia, ${ }^{2}$ Institute of Analytical and Bioanalytical Chemistry, \\ University of Ulm, Ulm, Germany and ${ }^{3}$ Faculty of Physics, M.V. \\ Lomonosov Moscow State University, Moscow, Russia \\ Email: \\ Oleg G. Voronin ${ }^{*}$ - ol.voronin@gmail.com \\ * Corresponding author \\ § Phone: +7 49593946 05; Fax: +7 4959394605 \\ Keywords: \\ energy related; hydrogen peroxide; nanomaterials; nickel \\ hexacyanoferrate; Prussian Blue; scanning electrochemical \\ microscopy; ultramicroelectrodes
}

Beilstein J. Nanotechnol. 2013, 4, 649-654.

doi:10.3762/bjnano.4.72

Received: 17 July 2013

Accepted: 22 September 2013

Published: 14 October 2013

This article is part of the Thematic Series "Energy-related nanomaterials".

Guest Editors: P. Ziemann and A. R. Khokhlov

(c) 2013 Komkova et al; licensee Beilstein-Institut.

License and terms: see end of document.

\begin{abstract}
We report here a way for improving the stability of ultramicroelectrodes (UME) based on hexacyanoferrate-modified metals for the detection of hydrogen peroxide. The most stable sensors were obtained by electrochemical deposition of six layers of hexacyanoferrates (HCF), more specifically, an alternating pattern of three layers of Prussian Blue and three layers of Ni-HCF. The microelectrodes modified with mixed layers were continuously monitored in $1 \mathrm{mM}$ hydrogen peroxide and proved to be stable for more than $5 \mathrm{~h}$ under these conditions. The mixed layer microelectrodes exhibited a stability which is five times as high as the stability of conventional Prussian Blue-modified UMEs. The sensitivity of the mixed layer sensor was $0.32 \mathrm{~A} \cdot \mathrm{M}^{-1} \cdot \mathrm{cm}^{-2}$, and the detection limit was $10 \mu \mathrm{M}$. The mixed layer-based UMEs were used as sensors in scanning electrochemical microscopy (SECM) experiments for imaging of hydrogen peroxide evolution.
\end{abstract}

\section{Introduction}

The detection of hydrogen peroxide $\left(\mathrm{H}_{2} \mathrm{O}_{2}\right)$ is of great importance in monitoring of food and the environment [1] as well as clinical [2], biological and chemical studies [3]. For example, hydrogen peroxide is a marker of inflammatory diseases [4].
Moreover, in fuel cells research, hydrogen peroxide is one of the key molecules as it is produced in the cathode chamber of the hydrogen-oxygen fuel cells causing degradation of the proton-exchange membranes [5]. Investigations of the local 
distribution of hydrogen peroxide on the surface of living cells and electrode materials as well as the in vivo analysis requires sensors with a size of $25 \mu \mathrm{m}$ and less. For such electrodes (ultramicroelectrodes, UME) the thickness of the diffusion layer is comparable to the diameter of the electrode resulting in enhanced mass transport in comparison to macroscopic electrodes and thus leading to improved sensitivity and detection limits [6].

There are a number of studies which demonstrate the detection of $\mathrm{H}_{2} \mathrm{O}_{2}$ in SECM experiments based on its oxidation at bare platinum electrodes at a potential of $600 \mathrm{mV}$ vs SCE [7-13]. However, such a high oxidation potential is often disadvantageous for real-world applications as interfering compounds may be co-oxidized. Prussian Blue (PB) is the most advantageous hydrogen peroxide transducer [14-16] due to its higher activity in $\mathrm{H}_{2} \mathrm{O}_{2}$ reduction and oxidation reactions, higher selectivity for hydrogen peroxide reduction in the presence of oxygen, and insensitivity to the presence of reducing compounds (e.g., ascorbate, paracetamol, etc.) [17]. We have already demonstrated miniaturized PB based electrodes with diameters ranging from $10 \mu \mathrm{m}$ [18] to $125 \mu \mathrm{m}$ [19]. For the electrodes with diameters of $125 \mu \mathrm{m}$, a record sensitivity of approximately $9 \mathrm{~A} \cdot \mathrm{M}^{-1} \cdot \mathrm{cm}^{-2}$ in $\mathrm{H}_{2} \mathrm{O}_{2}$ detection was achieved. However, the stability of $\mathrm{PB}$ in neutral aqueous solutions is not sufficient in respect to the long-term continuous monitoring of high levels of $\mathrm{H}_{2} \mathrm{O}_{2}$ [20]. Moreover, different iron complexing agents (e.g., EDTA) are known to solubilize PB. This problem is particularly severe for PB-modified UME.

Operational stability of the PB can be improved by covering its surface with polymer films $[21,22]$, by entrapment of the catalysts into sol-gel [23-25], and by conductive polymer matrixes $[26,27]$. In [20] we have demonstrated a novel approach for the stabilization of a sensor based on mixed iron-nickel hexacyanoferrates. Here, we report on the highly stable ultramicrosensors comprised of alternating films of iron and nickel hexacyanoferrates for the imaging of hydrogen peroxide distribution in SECM.

\section{Results and Discussion}

Hexacyanoferrates were deposited onto UMEs with a diameter of $10 \mu \mathrm{m}$ and $25 \mu \mathrm{m}$, respectively. Three types of UME were used: (i) carbon, (ii) platinum and (iii) platinum covered with an ion beam induced deposition (IBID)-generated $\mathrm{Pt} / \mathrm{C}$ composite material [28]. Deposition of PB was carried out by using cyclic voltammetry (CV) as described elsewhere in detail [29]. PB was deposited using 5 cycles. A further increase of cycles led to a decreased stability. In spite of the good selectivity, PB-based electrodes showed low operational stability in batch measurements (see Table 1).

Stabilized sensors were obtained by using a layer-by-layer deposition with mixed layers of $\mathrm{PB}$ and $\mathrm{Ni}-\mathrm{HCF} . \mathrm{Ni}^{2+}$ and $\mathrm{Fe}(\mathrm{CN})_{6}{ }^{3-}$ ions tend to form insoluble precipitate in pure aqueous solutions. Therefore an excessive amount of supporting electrolyte $(0.5 \mathrm{M} \mathrm{KCl})$ was used during the deposition of $\mathrm{Ni}-\mathrm{HCF}$ films. Deposition of Ni-HCF was performed by using $\mathrm{CV}$ as described elsewhere [20]. Every two cycles of PB deposition were followed by 2 cycles of Ni-HCF deposition forming one "bilayer". AFM images of Prussian blue and Ni-HCF deposited on top are shown in Figure 1. After the last deposition step the electrodes were activated by $\mathrm{CV}$ as described in the Experimental section of this manuscript.
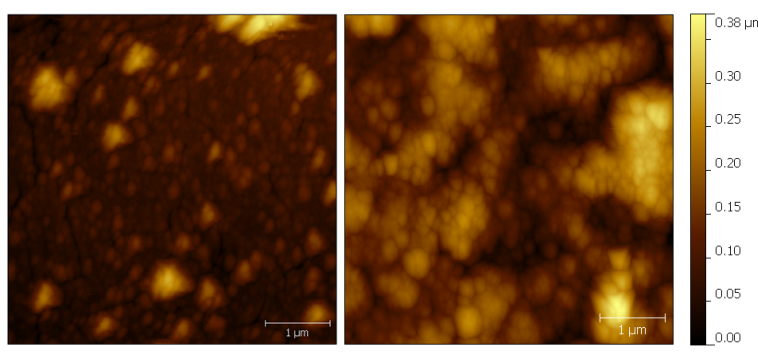

Figure 1: AFM topography images of Prussian blue layer (left) and $\mathrm{Ni}-\mathrm{HCF}$ layer (right) deposited on top (contact mode images were recorded in air with 0.3 lines/s at a resolution of $512 \times 512$ lines/ image).

Table 1: Sensitivity and operational stability of the ultramicrosensors ( $\mathrm{pH}$, batch regime)

\begin{tabular}{|c|c|c|c|}
\hline type of UME & type of film & sensitivity, $\mathrm{mA} / \mathrm{cm}^{2}$ & stability in $1 \mathrm{mM}$ of $\mathrm{H}_{2} \mathrm{O}_{2}$, $\min$ \\
\hline glassy carbon & PB & 1600 & 10 \\
\hline glassy carbon & PB-Ni-HCF & 81 & 240 \\
\hline platinum & PB & 1050 & 15 \\
\hline platinum & $\mathrm{PB}-\mathrm{Ni}-\mathrm{HCF}$ & 320 & 240 \\
\hline ion deposited Pt-C composite & PB & 760 & 60 \\
\hline ion deposited $\mathrm{Pt}-\mathrm{C}$ composite & PB-Ni-HCF & 100 & 300 \\
\hline
\end{tabular}


Increasing the number of bilayers from one to three resulted in a higher sensitivity of the modified electrodes. A continued increase of the number of $\mathrm{PB}-\mathrm{Ni}-\mathrm{HCF}$ bilayers resulted in a loss of mechanical stability. Therefore, all further experiments were carried out with electrodes modified with three bilayers. A typical cyclic voltammogram of a 3-layer-modified microelectrode in supporting electrolyte solution is shown in Figure 2.

Table 1 summarizes the comparison of sensitivity and stability of $\mathrm{PB}-\mathrm{Ni}-\mathrm{HCF}-\mathrm{sensors}$ using different electrode materials with data for UMEs only modified with PB. The measurements were carried out in a batch regime. The sensors with mixed layers showed a significantly improved stability and an expected decrease in sensitivity. Figure 3 shows an exemplary calibration curve for a microsensor based on $\mathrm{PB}-\mathrm{Ni}-\mathrm{HCF}$ mixed layers deposited on a platinum UME (diam. of $25 \mu \mathrm{m}$ ).

PB-Ni-HCF-modified platinum microelectrodes were also applied in SECM experiments to map hydrogen peroxide profiles in substrate-generation-tip-collection mode (see Figure 4). As clearly visible in the SECM image, the reduction current significantly increased when the PB-Ni-modified electrode was scanned towards the center of the $\mathrm{H}_{2} \mathrm{O}_{2}$-generating

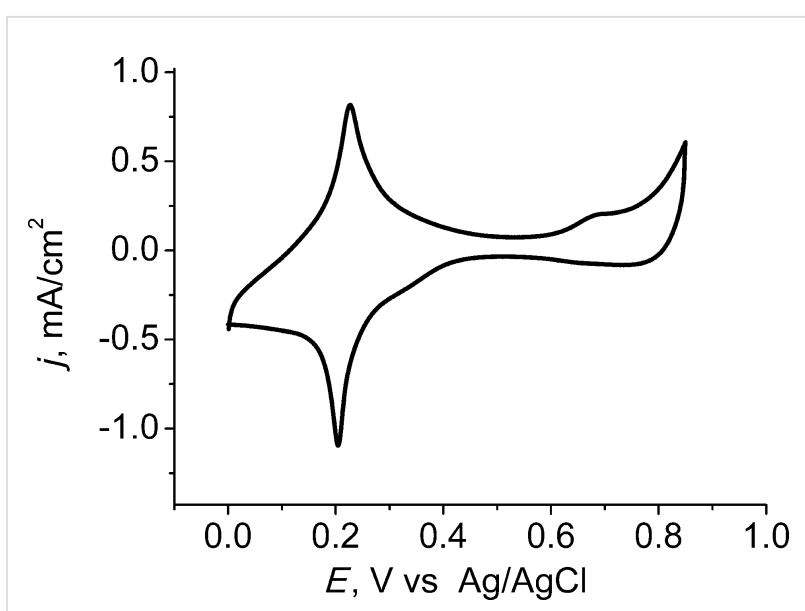

Figure 2: Cyclic voltammogram of three PB-Ni-HCF bilayers deposited on a platinum ultramictroelectrode $(0.1 \mathrm{M} \mathrm{KCl}$ and $0.1 \mathrm{M} \mathrm{HCl}$, sweep rate $\left.20 \mathrm{mV} \cdot \mathrm{s}^{-1}\right)$.

gold electrode (Figure 4A). Control experiments were carried out by repeated SECM scans with three different scanning electrodes: (i) a blank platinum electrode (biased at $0 \mathrm{~V}$ vs $\mathrm{Ag} / \mathrm{AgCl}$ ), (ii) a platinum electrode modified only with $\mathrm{Ni}-\mathrm{HCF}$, and (iii) a PB-Ni-HCF-modified UME with no poten-

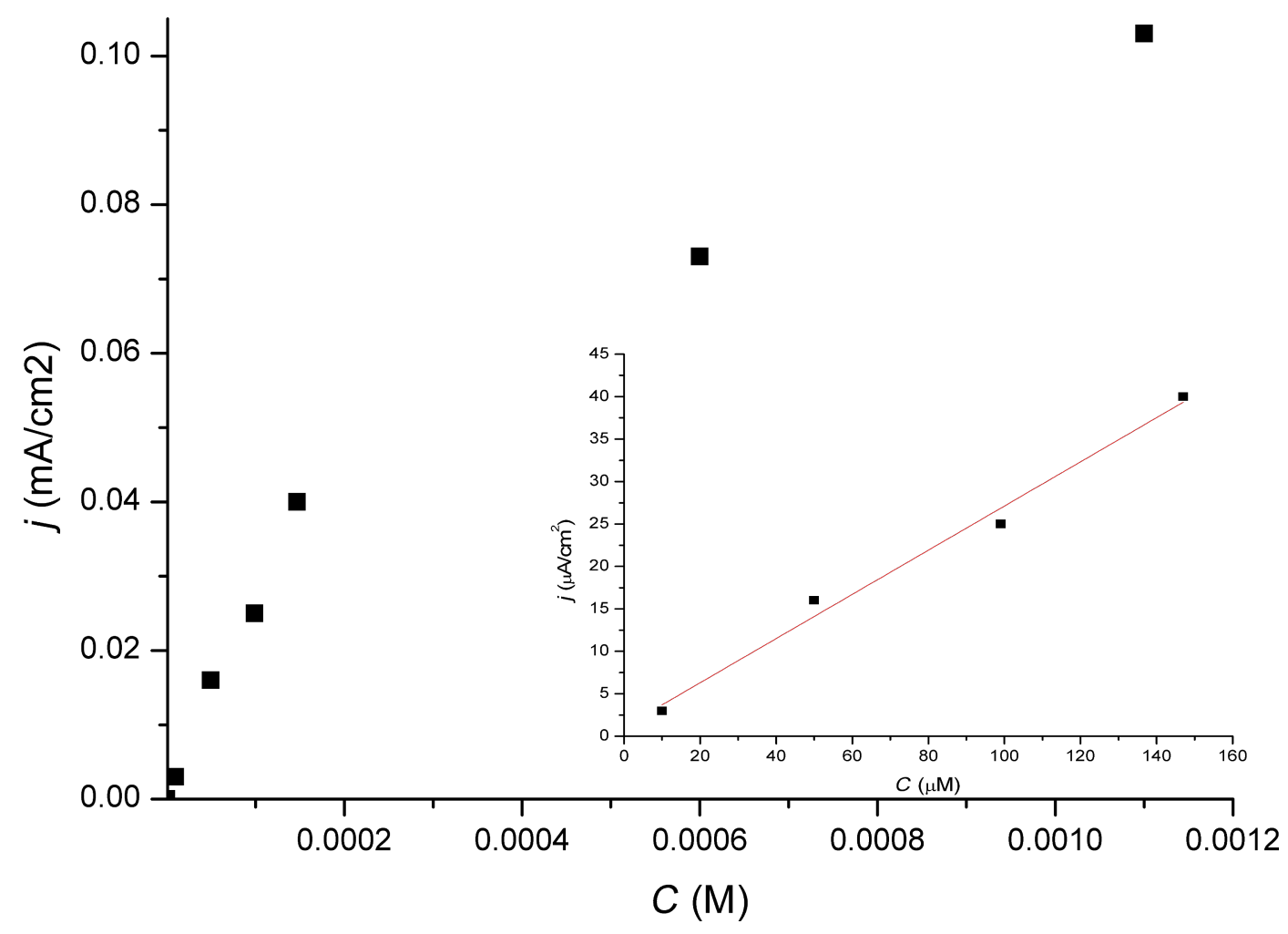

Figure 3: Standard addition curve for hydrogen peroxide recorded at $0 \mathrm{mV}$ vs $\mathrm{Ag} / \mathrm{AgCl}$ at a platinum UME (diam. of $25 \mu \mathrm{m}$ ) covered with three bilayers of PB-Ni-HCFs. 

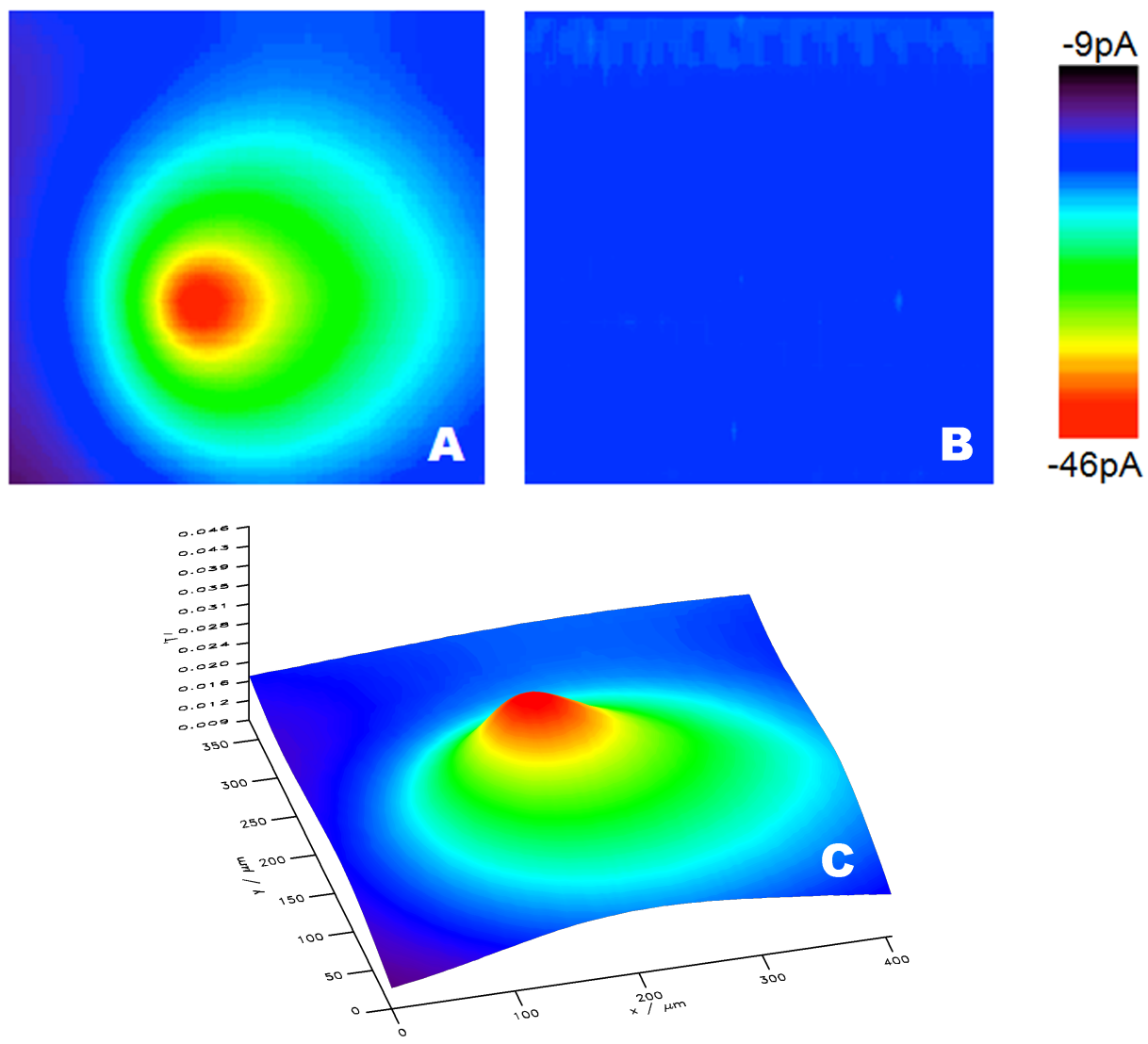

Figure 4: SECM image of an $\mathrm{H}_{2} \mathrm{O}_{2}$-generating gold electrode (diam. of $25 \mu \mathrm{m}$ ). A and $\mathrm{B}$ are $2 \mathrm{D}$ plots of images recorded with a platinum UME (diam. of $25 \mu \mathrm{m}$ ) covered with three layers of PB-Ni-HCF and with Ni-HCF, respectively. C illustrates a 3D plot of A.

tial applied to the $\mathrm{H}_{2} \mathrm{O}_{2}$ generating gold electrode. In all control experiments a significant signal was not recorded. After the imaging experiments, the integrity of the film was confirmed by $\mathrm{CV}$ recorded in $0.1 \mathrm{M} \mathrm{HCl} / \mathrm{KCl}$.

\section{Conclusion}

Ultramicrosensors for the detection of hydrogen peroxide with increased stability have been developed. It was shown that the electrodeposition of multiple $\mathrm{PB}-\mathrm{Ni}-\mathrm{HCF}$ bilayers on UME provides a significantly enhanced stability of the electrocatalytic films for different electrode materials. UMEs modified with PB-Ni-HCF films retained more than $95 \%$ of the initial catalytic activity during at least 5 hours continuous monitoring in $1 \mathrm{mM}$ hydrogen peroxide.

\section{Experimental}

Experiments were carried out in solutions prepared with Millipore water (resistivity $18.2 \mathrm{M} \Omega$ ). All inorganic salts, organic solvents, and hydrogen peroxide ( $30 \%$ solution) were obtained at the highest purity from Sigma-Aldrich. Polishing materials were obtained from Leco Instruments $\mathrm{GmbH}$ and Allied High Tech Products Inc. Gold and platinum microwires were purchased from Goodfellow. The micro glassy carbon electrodes were obtained from ESA Biosciences Inc.

The electrochemical experiments were conducted in a threeelectrode setup using either a CHI842B bipotentiostat or a $\mu$-Autolab Type III (Eco Chemie) potentiostat as described in detail elsewhere [18]. $\mathrm{An} \mathrm{Ag} / \mathrm{AgCl}$ was used as a reference electrode and platinum was used as a counter electrode.

Microelectrodes were prepared as described elsewhere [30] by sealing platinum or gold wires $(25 \mu \mathrm{m}$ and $10 \mu \mathrm{m}$ in diameter, respectively) under vacuum in borosilicate glass (Hilgenberg) or soda lime glass, respectively, followed by consecutive grinding, and polishing steps. Electrodes were then cleaned in an ultrasonic bath for 15 minutes. Circular $\mathrm{Pt} / \mathrm{C}$ composite layers were deposited onto a microelectrode using a focused ion beam gas-assisted process (Quanta 3D FEG, FEI Eindhoven). The circular Pt/C composite were deposited on $10 \mu \mathrm{m}$ Pt elec- 
trodes and had a radius of approx. $6.5 \mu \mathrm{m}$ and a thickness of approx. $150 \mathrm{~nm}$ (ion beam current: $300 \mathrm{pA}$ and a dwell time of $200 \mathrm{~ns}$ ) with a ratio of carbon to platinum in the range of 60 atom \% C to 24 atom \% Pt [28]. Cyclic voltammetry, optical microscopy, and AFM (5500 AFM, Agilent Technologies) imaging were performed for characterizing the fabricated microelectrodes.

The deposition of PB was carried out as described in detail elsewhere [18]. The electrodeposition of nickel hexacyanoferrate (NiHCF) was carried out in a non-colloid solution containing $1 \mathrm{mM} \mathrm{NiCl} 2$ and $0.5 \mathrm{mM} \mathrm{K}_{3}\left[\mathrm{Fe}(\mathrm{CN})_{6}\right]$ with an excessive amount of supporting electrolyte $(0.1 \mathrm{M} \mathrm{HCl}$ and $0.5 \mathrm{M} \mathrm{KCl})$, while cycling the electrode potential between 0 and $0.85 \mathrm{~V}$ at a scan rate of $100 \mathrm{mV} / \mathrm{s}$ applying 20 scans. After the deposition of $\mathrm{NiHCF}$, the electrodes were rinsed with MilliQ water (Millipore MilliQ system) and and tempered at $80^{\circ} \mathrm{C}$ for $0.5 \mathrm{~h}$.

The deposition of the mixed films was performed as follows. First, a layer of PB was deposited by cyclic voltammetry as described above applying 2 scans. The electrodes were rinsed with distilled water and dried at $80{ }^{\circ} \mathrm{C}$ for $15 \mathrm{~min}$. Then, the deposition of NiHCF was carried out by cyclic voltammetry applying 2 cycles. All layers (except the first and the last ones) were synthesized without temperature treatment. The activation was carried out by $\mathrm{CV}$ applying 10 cycles in $0.1 \mathrm{M} \mathrm{KCl}$ and $0.1 \mathrm{M} \mathrm{HCl}$ solution within the limits of 0.00 to $+0.85 \mathrm{~V}$ at a scan rate of $40 \mathrm{mV} / \mathrm{s}$ and was performed after electrosynthesis of the last layer. Then the electrodes were dried at $80{ }^{\circ} \mathrm{C}$ for $0.5 \mathrm{~h}$.

SECM measurements were performed in generation-collection mode as described in detail elsewhere [18]. A gold microelectrode ( $25 \mu \mathrm{m}$ in diameter) was used for generating hydrogen peroxide (bias: $-0.4 \mathrm{~V}$ vs $\mathrm{Ag} / \mathrm{AgCl}$ ). Platinum microelectrodes covered with $\mathrm{PB}, \mathrm{PB} / \mathrm{NiHCF}$ and $\mathrm{NiHCF}$ were used to detect the reduction current of hydrogen peroxide at $0.00 \mathrm{~V}$ vs $\mathrm{Ag} / \mathrm{AgCl}$. The microelectrode modified by metal cyanoferrate was positioned in close proximity to the hydrogen peroxide generating UME in feedback mode recording the Faraday current of the Au microelectrode during the approach of the modified electrode. Prior to the approach curve, the electrodes were positioned centered to each other using an optical microscope. The non-biased modified UME was then approached to the $\mathrm{Au}$ microelectrode while the feedback current at the $\mathrm{Au}$ UME was recorded in $10 \mathrm{mM}$ ferrocyanide/ $0.1 \mathrm{M} \mathrm{KCl}$. A negative feedback signal was obtained due to the hindered diffusion of ferrocyanide towards the Au UME when the modified electrode is in the vicinity. The SECM image was then recorded in constant-height mode at a distance of $50 \mu \mathrm{m}$ (determined by Mira software package, G. Wittstock, University of Oldenburg).

\section{Acknowledgements}

Financial support of the Bundesministerium für Bildung und Forschung (project RUS 09/036) and the Russian Ministry for Science and Education (contract no.14.740.11.1374) are gratefully acknowledged. Gregor Neusser and FIB Center Ulm are acknowledged for $\mathrm{Pt}-\mathrm{C}$ depositions.

\section{References}

1. Anglada, J. M.; Aplincourt, P.; Bofill, J. M.; Cremer, D. ChemPhysChem 2002, 3, 215-221. doi:10.1002/1439-7641(20020215)3:2<215::AID-CPHC215>3.0.CO;2-3

2. Camci-Unal, G.; Alemdar, N.; Annabi, N.; Khademhosseini, A. Polym. Int. 2013, 62, 843-848. doi:10.1002/pi.4502

3. Gomes, M. P.; Garcia, Q. S. Biologia (Warsaw, Pol.) 2013, 68, 351-357. doi:10.2478/s11756-013-0161-y

4. Majewska, E.; Kasielski, M.; Luczynski, R.; Bartosz, G.; Bialasiewicz, P.; Nowak, D. Respir. Med. 2004, 98, 669-676. doi:10.1016/j.rmed.2003.08.015

5. Mu, S.; Xu, C.; Yuan, Q.; Gao, Y.; Xu, F.; Zhao, P. J. Appl. Polym. Sci. 2013, 129, 1586-1592. doi:10.1002/app.38785

6. Bard, A. J.; Faulkner, L. R. Electrochemical Methods: Fundamentals and Applications, 2nd ed.; John Wiley \& Sons: New York, U.S., 2001.

7. Kranz, C.; Wittstock, G.; Wohlschläger, H.; Schuhmann, W. Electrochim. Acta 1997, 42, 3105-3111. doi:10.1016/S0013-4686(97)00158-8

8. Pierce, D. T.; Unwin, P. R.; Bard, A. J. Anal. Chem. 1992, 64, 1795-1804. doi:10.1021/ac00041a011

9. Wittstock, G.; Wilhelm, T.; Bahrs, S.; Steinrücke, P. Electroanalysis 2001, 13, 669-675. doi:10.1002/1521-4109(200105)13:8/9<669::AID-ELAN669>3.0.CO;2$\mathrm{S}$

10. Wittstock, G.; Schuhmann, W. Anal. Chem. 1997, 69, 5059-5066. doi:10.1021/ac970504o

11. Kishi, A.; Inoue, M.; Umeda, M. J. Phys. Chem. C 2009, 114, 1110-1116. doi:10.1021/jp909010q

12. Eckhard, K.; Schuhmann, W. Electrochim. Acta 2007, 53, 1164-1169. doi:10.1016/j.electacta.2007.02.028

13. Fernández, J. L.; Bard, A. J. Anal. Chem. 2003, 75, 2967-2974. doi:10.1021/ac0340354

14. Karyakin, A. A.; Gitelmacher, O. V.; Karyakina, E. E. Anal. Chem. 1995, 67, 2419-2423. doi:10.1021/ac00110a016

15. Karyakin, A. A.; Karyakina, E. E. Sens. Actuators, B 1999, 57, 268-273. doi:10.1016/S0925-4005(99)00154-9

16. Karyakin, A. A.; Karyakina, E. E.; Gorton, L. Anal. Chem. 2000, 72, 1720-1723. doi:10.1021/ac9908010

17. Kozlovskaja, S.; Baltrūnas, G.; Malinauskas, A. Microchim. Acta 2009, 166, 229-234. doi:10.1007/s00604-009-0185-8

18. Voronin, O. G.; Hartmann, A.; Steinbach, C.; Karyakin, A. A.; Khokhlov, A. R.; Kranz, C. Electrochem. Commun. 2012, 23, 102-105. doi:10.1016/j.elecom.2012.07.017

19. Mokrushina, A. V.; Heim, M.; Karyakina, E. E.; Kuhn, A.; Karyakin, A. A. Electrochem. Commun. 2013, 29, 78-80. doi:10.1016/j.elecom.2013.01.004

20. Sitnikova, N. A.; Borisova, A. V.; Komkova, M. A.; Karyakin, A. A. Anal. Chem. 2011, 83, 2359-2363. doi:10.1021/ac1033352

21. García-Jareño, J. J.; Navarro-Laboulais, J.; Vicente, F. Electrochim. Acta 1996, 41, 2675-2682. doi:10.1016/0013-4686(96)00121-1 
22. Lukachova, L. V.; Kotel'nikova, E. A.; D'Ottavi, D.; Shkerin, E. A.; Karyakinia, E. E.; Moscone, D.; Palleschi, G.; Curulli, A.; Karyakin, A. A. Bioelectrochemistry 2002, 55, 145-148. doi:10.1016/S1567-5394(01)00146-3

23. Bharathi, S.; Lev, O. Appl. Biochem. Biotechnol. 2000, 89, 209-216. doi:10.1385/ABAB:89:2-3:209

24. Guo, Y. Z.; Guadalupe, A. R.; Resto, O.; Fonseca, L. F.; Weisz, S. Z. Chem. Mater. 1999, 11, 135-140. doi:10.1021/cm9806275

25. Salimi, A.; Abdi, K. Talanta 2004, 63, 475-483. doi:10.1016/j.talanta.2003.11.021

26. Borisova, A. V.; Karyakina, E. E.; Cosnier, S.; Karyakin, A. A. Electroanalysis 2009, 21, 409-414. doi:10.1002/elan.200804408

27. Koncki, R.; Wolfbeis, O. S. Anal. Chem. 1998, 70, 2544-2550. doi:10.1021/ac9712714

28. Wiedemair, J.; Menegazzo, N.; Pikarsky, J.; Booksh, K. S.; Mizaikoff, B.; Kranz, C. Electrochim. Acta 2010, 55, 5725-5732. doi:10.1016/j.electacta.2010.05.008

29. Karyakin, A. A.; Kuritsyna, E. A.; Karyakina, E. E.; Sukhanov, V. L. Electrochim. Acta 2009, 54, 5048-5052. doi:10.1016/j.electacta.2008.11.049

30. Rudolph, D.; Neuhuber, S.; Kranz, C.; Taillefert, M.; Mizaikoff, B. Analyst 2004, 129, 443-448. doi:10.1039/b400051j

\section{License and Terms}

This is an Open Access article under the terms of the Creative Commons Attribution License

(http://creativecommons.org/licenses/by/2.0), which permits unrestricted use, distribution, and reproduction in any medium, provided the original work is properly cited.

The license is subject to the Beilstein Journal of

Nanotechnology terms and conditions:

(http://www.beilstein-journals.org/bjnano)

The definitive version of this article is the electronic one which can be found at:

doi:10.3762/bjnano.4.72 